\title{
Graphene Oxide Functional Nanohybrids with Magnetic Nanoparticles for Improved Vectorization of Doxorubicin to Neuroblastoma Cells
}

\author{
Luigi Lerra ${ }^{1}$, Annafranca Farfalla ${ }^{2}$, Beatriz Sanz ${ }^{3}$, Giuseppe Cirillo ${ }^{2, *}$, Orazio Vittorio ${ }^{1,4,5}$, \\ Florida Voli ${ }^{1}$, Marion Le Grand ${ }^{1,4,5}$, Manuela Curcio ${ }^{2}$, Fiore Pasquale Nicoletta ${ }^{2}{ }^{\circ}$, \\ Anna Dubrovska ${ }^{6,7,8,9}$, Silke Hampel ${ }^{10}$, Francesca Iemma ${ }^{2}$ and Gerardo F. Goya ${ }^{11}$ (1)
}

1 Children's Cancer Institute, Lowy Cancer Research Centre, UNSW Sydney, NSW 2031, Australia; LLerra@ccia.org.au (L.L.); OVittorio@ccia.org.au (O.V.); FVoli@ccia.org.au (F.V.);

MLeGrand@ccia.org.au (M.L.G.)

2 Department of Pharmacy Health and Nutritional Science, University of Calabria, 87036 Rende (CS), Italy; annafranca.farfalla@gmail.com (A.F.); manuela.curcio@unical.it (M.C.); fiore.nicoletta@unical.it (F.P.N.); francesca.iemma@unical.it (F.I.)

3 nB nanoSacale Biomagnetics SL, 50012 Zaragoza, Spain; bsanzsague@gmail.com

4 ARC Centre of Excellence for Convergent BioNano Science and Technology, Australian Centre for NanoMedicine, UNSW Sydney, NSW 2052, Australia

5 School of Women's and Children's Health, Faculty of Medicine, UNSW Sydney, NSW 2052, Australia

6 OncoRay-National Center for Radiation Research in Oncology, Faculty of Medicine and University Hospital Carl Gustav Carus, Technische Universität Dresden, 01307 Dresden, Germany; Anna.Dubrovska@OncoRay.de

7 German Cancer Research Center (DKFZ), 69120 Heidelberg, Germany

8 German Cancer Consortium (DKTK), partner site Dresden, 01307 Dresden, Germany

9 Helmholtz-Zentrum Dresden-Rossendorf, Institute of Radiooncology-Oncoray, 01307 Dresden, Germany

10 Leibniz Institute of Solid State and Material Research Dresden, 01069 Dresden, Germany; s.hampel@ifw-dresden.de

11 Institute of Nanoscience of Aragon (INA), Department of Condensed Matter Physics, University of Zaragoza, 50018 Zaragoza, Spain; goya@unizar.es

* Correspondence: giuseppe.cirillo@unical.it; Tel.: +39-0984-493011

Received: 27 November 2018; Accepted: 18 December 2018; Published: 22 December 2018

\begin{abstract}
With the aim to obtain a site-specific doxorubicin (DOX) delivery in neuroblastoma SH-SY5Y cells, we designed an hybrid nanocarrier combining graphene oxide (GO) and magnetic iron oxide nanoparticles (MNPs), acting as core elements, and a curcumin-human serum albumin conjugate as functional coating. The nanohybrid, synthesized by redox reaction between the MNPs@GO system and albumin bioconjugate, consisted of MNPs@GO nanosheets homogeneously coated by the bioconjugate as verified by SEM investigations. Drug release experiments showed a $\mathrm{pH}$-responsive behavior with higher release amounts in acidic $(45 \%$ at $\mathrm{pH} 5.0)$ vs. neutral $(28 \%$ at $\mathrm{pH} 7.4)$ environments. Cell internalization studies proved the presence of nanohybrid inside SH-SY5Y cytoplasm. The improved efficacy obtained in viability assays is given by the synergy of functional coating and MNPs constituting the nanohybrids: while curcumin moieties were able to keep low DOX cytotoxicity levels (at concentrations of $0.44-0.88 \mu \mathrm{M}$ ), the presence of MNPs allowed remote actuation on the nanohybrid by a magnetic field, increasing the dose delivered at the target site.
\end{abstract}

Keywords: graphene oxide; iron oxide nanoparticles; magnetic targeting; nanohybrids; synergism 


\section{Introduction}

Patients with neuroblastoma, the third most common type of extracranial solid cancer in the pediatric population [1], suffer for the severe acute and chronic toxicity of commonly employed therapeutics (e.g., vinca alkaloids, platinum drugs, and anthracyclines) due to the nonspecific in vivo distribution and their serious side effects [2,3]. The intravenous administration of conventional chemotherapy does not distinguish between cancerous and healthy cells and, especially in the case of childhood tumors, targeted and less toxic therapies are urgently required in order to improve the quality of life and reduce the lifelong health issues for the survivors [4,5]. To this regard, a great hope lies in the rising synergy between biomedicine and nanotechnology [6] with the possibility to develop delivery vehicles able to localize the delivery of payload in the tumor site $[7,8]$.

In this work, we combined graphene oxide (GO), iron oxide nanoparticles (MNPs), and a new human serum albumin-curcumin conjugate (C@HSA) for the fabrication of a novel multifunctional nanohybrid (C@HSA-MNPs@rGO) to spatially control the vectorization of doxorubicin (DOX) to neuroblastoma SH-SY5Y cells. Due to its specific features, each component was observed to contribute to the performance of the final nanohybrid: (1) MNPs act as a targeting element [9-11]; (2) GO enhances the drug loading capability and makes the release profile prolonged over time [12-15]; and (3) immobilized curcumin (CUR) in the functional coating synergizes the drug cytotoxicity [16-18].

Due to their capability to interact with remote magnetic fields, magnetic nanoparticles are used in a growing number of strategies to actuate on biological systems for both diagnostic and therapeutic purposes [19-22]. Similarly, the use of GO-based nanomaterials as cargo bays for drug vectorization has grown rapidly in the past several years, by virtue of its unique structural and physic-chemical properties, excellent biocompatibility, large surface area, and low cost [23-27]. We previously proved that the coating of carbon nanostructures with polyphenol-polymer conjugates constituted an efficient drug delivery system whose anticancer activity is related to either the loaded drug or the carrier itself $[28,29]$. The resulting nanohybrid described here profits from two main concurrent effects: (1) the synergistic mechanism of polyphenols associated with conventional anticancer drugs [30,31], and (2) the possibility to finely tune the drug release according to the carrier properties [32,33].

The experimental protocol involved the synthesis of MNPs stabilized with polyethyleneimine, and their subsequent mounting on GO sheets. Thus, MNPs@GO was loaded with doxorubicin and finally coated with a C@HSA to obtain the final nanohybrid, characterized in terms of physico chemical and magnetic properties and in vitro anticancer performance, providing new effective opportunities for targeted drug delivery.

\section{Materials and Methods}

\subsection{Preparation of Graphene Oxide}

A modified Hummers method was employed for the preparation of GO [34]. One gram of graphite (99.99\%, 200 mesh), exfoliated by grinding with $50.0 \mathrm{~g} \mathrm{NaCl}$ for $10 \mathrm{~min}$, freed from $\mathrm{NaCl}$ by dissolution in distilled water $\left(40^{\circ} \mathrm{C}\right)$ and recovered by filtration using a $450 \mathrm{~nm}$ porous TEFLON filter paper, was mixed with $23 \mathrm{~mL} \mathrm{H}_{2} \mathrm{SO}_{4}(96 \% w / w)$ overnight to allow graphite layers being intercalated by $\mathrm{H}_{2} \mathrm{SO}_{4}$.

The oxidization process was performed by adding $3.0 \mathrm{~g} \mathrm{KMnO}_{4}$ over $3 \mathrm{~h}$ under constant stirring, and then the suspension was sonicated for $3 \mathrm{~h}$ and continuously stirred for $30 \mathrm{~min}$ at $35^{\circ} \mathrm{C}$ and $45 \mathrm{~min}$ at $50{ }^{\circ} \mathrm{C}$, respectively. Then, the suspension was added with distilled water $(46 \mathrm{~mL})$ and stirred for $45 \mathrm{~min}$ under reflux. After cooling to room temperature, distilled water $(140 \mathrm{~mL})$ and $\mathrm{H}_{2} \mathrm{O}_{2}(10 \mathrm{~mL}$, $30 \%$ ) were added to reduce the residual permanganate and manganese dioxide to manganese sulfate. The resulting material, filtered and washed 5 times with $5 \% \mathrm{HCl}$ and distilled water to remove any reaction by-products, was cracked in water using a horn-tipped ultrasonic probe at $28 \mathrm{~W}$ for $2 \mathrm{~h}$, in order to reduce the dimensions of the exfoliated GO sheets in terms of both lateral width and height. Uniformly sized GO particles $(100 \mathrm{~nm})$ were obtained via sucrose density gradient centrifugation. 
In a standard procedure, GO particles $(335 \mathrm{~mL})$ were added on the top of a gradient sucrose solutions $(20-60 \% w / v)$, gently dropped into the bottom of centrifuged tube. The tube was directly centrifuged under controlled conditions (6000 $\mathrm{g}$ for $5 \mathrm{~min}$ ) using Beckman Coulter, Allegra $64 \mathrm{R}$ centrifuge, and the $\mathrm{GO}$ recovered by rinsing thoroughly with distilled water to remove sucrose.

All chemicals were from Merck KGaA (Darmstadt, Germany) for synthesis.

\subsection{Synthesis of Magnetic Nanoparticles}

The poly(ethyleneimine) (PEI)-coated magnetic nanoparticles (MNPs) were synthesized following the modified oxidative hydrolysis method [35]. The main steps of this protocol are as follows: a solution containing iron (II) sulphate heptahydrate $\left(\mathrm{FeSO}_{4} \cdot 7 \mathrm{H}_{2} \mathrm{O}\right)$ and (PEI, $\left.\mathrm{Mw}=25 \mathrm{kDa}\right)$ is added dropwise over a basic solution with a mild oxidant under continuous mechanic stirring. Both solutions are mixed in a three-necked flask where a flux of $\mathrm{N}_{2}$ was bubbled. The synthesis temperature is maintained at $90^{\circ} \mathrm{C}$ for $24 \mathrm{~h}$, and after this time the PEI-MNPs are collected using a magnet and washed with deionized water several times to maintain the physiological $\mathrm{pH}$.

All chemicals used for the synthesis were purchased from Merck KGaA (Darmstadt, Germany).

\subsection{Laccase Immobilization}

The immobilization of Laccase was carried out as previously reported [36]. Twenty-five milligrams of laccase from Trametes versicolor (EC 1.10.3.2) were dissolved in $3.0 \mathrm{~mL}$ sodium citrate buffer solution $\left(10^{-3} \mathrm{~mol} \mathrm{~L}^{-1}, \mathrm{pH} 5.0\right)$ in the presence of $534 \mathrm{mg}$ acrylamide and then, $466 \mathrm{mg}$ polyethylene glycol dimethacrylate 750 and 2.4\% 1-[4-(2-hydroxyethoxy)-phenyl]-2-hydroxy-2-methyl-1-propane-1-one (Irgacure 2959, with a maximum absorption at around $275 \mathrm{~nm}$ ) were added as crosslinker and photo-initiator, respectively. After pouring in a reaction cell consisting of two $10 \times 10 \mathrm{~cm}^{2}$ glass plates brought together by binder clips and separated with Teflon spacers (thickness $1.6 \mathrm{~mm}$ ), the solution was polymerized by using a high pressure mercury lamp (HPK 125, Philips, Amsterdam, The Netherlands, $10 \mathrm{~mW} \mathrm{~cm}^{-2}$, wavelength $275 \mathrm{~nm}$, irradiation time $10 \mathrm{~min}$ ). The resulting hydrogel was freed from unreacted species by washing with distilled water and then dried for $12 \mathrm{~h}$ in an oven under vacuum at $40{ }^{\circ} \mathrm{C}$.

Irgacure 2959 was from BASF, Ludwigshafen, Germany, all other chemicals from Merck KGaA (Darmstadt, Germany).

\subsection{Synthesis and Characterization of the C@HSA Conjugate}

C@HSA was synthesized via enzyme catalysis as follows: $500 \mathrm{mg}$ HSA and $60 \mathrm{mg}$ curcumin (CUR) were dissolved in $20 \mathrm{~mL}$ phosphate buffer solution $\left(10^{-3} \mathrm{~mol} \mathrm{~L}^{-1}, \mathrm{pH}\right.$ 6.8)/DMSO mixture $75 / 25$ by volume and reacted by adding immobilized laccase $(500 \mathrm{mg}, 0.23 \mathrm{U})$ at $37^{\circ} \mathrm{C}$ under $70 \mathrm{rpm}$ for $12 \mathrm{~h}$. The conjugate was purified by dialysis process (dialysis tubes of 6-27/32" Medicell International LTD (Liverpool, UK), MWCO: 12,000-14,000 Da) and dipped into a glass vessel containing distilled water at room temperature for $72 \mathrm{~h}$, until complete removal of unreacted CUR in the washing media was confirmed by high-pressure liquid chromatography (HPLC) analysis. The resulting solutions were frozen and dried with a freeze drier (Micro Modulyo, Edwards Lifesciences, Irvine, CA, USA) to afford vaporous solids.

The HPLC analysis conditions were: Jasco PU-2089 Plus liquid chromatography equipped with a Rheodyne 7725i injector (fitted with a $20 \mu \mathrm{L}$ loop), a Jasco UV-2075 HPLC detector operating at $420 \mathrm{~nm}$, Jasco-Borwin integrator (Jasco Europe s.r.l., Milan, Italy), and a Tracer Excel 120 ODS-A column particle size $5 \mu \mathrm{m}, 15 \times 0.4 \mathrm{~cm}$ (Barcelona, Spain), mobile phase consisting of methanol at a flow rate of $1.0 \mathrm{~mL} \mathrm{~min}^{-1}$ [37].

The (2,4,6)-trinitrobenzenesulfonic acid (TNBS) assay was used to determine the free amino groups in HSA and C@HSA, and thus to indirectly calculate the functionalization degree expressed as $\mathrm{mg}$ of CUR per g of conjugate [38]. Briefly, $0.5 \mathrm{~mL} 2,4,6$-trinitrobenzenesulfonic acid solution $(0.01 \% \mathrm{w} / \mathrm{v})$ were added to $1.0 \mathrm{mg} \mathrm{NaHCO} 3\left(0.1 \mathrm{~mol} \mathrm{~L}^{-1}, \mathrm{pH} 8.5\right)$ containing HSA or C@HSA $\left(2.0 \mathrm{mg} \mathrm{mL}^{-1}\right)$ 
and, after mixing in the dark, placed in a water bath at $37^{\circ} \mathrm{C}$ for $4 \mathrm{~h}$ under shaking. Then, SDS $(50 \mu \mathrm{L}$, $\left.0.35 \mathrm{~mol} \mathrm{~L}^{-1}\right)$ and $\mathrm{HCl}\left(25 \mu \mathrm{L}, 1 \mathrm{~mol} \mathrm{~L}^{-1}\right)$ were added to terminate the reaction the absorbance measured at $335 \mathrm{~nm}$ on the V-530 Jasco UV-Vis spectrophotometer operating with $1.0 \mathrm{~cm}$ quartz cells (Jasco Europe, Milan, Italy). The amount (mg) of CUR in C@HSA was calculated according to Equation (1):

$$
m g_{\text {CUR }}=\frac{A_{0}-A_{1}}{A_{0}} \times n_{\mathrm{NH}_{2}}^{0} \times M W_{\mathrm{CUR}}
$$

Here, $n_{\mathrm{NH}_{2}}^{0}$ refers to the amount of $\mathrm{NH}_{2}$ groups in the HSA, $M W_{C U R}$ the molecular weight of CUR, and $A_{0}$ and $A_{1}$ the absorbance of HSA and C@HSA, respectively.

All chemicals were from Merck/Sigma Aldrich, Germany.

\subsection{Synthesis and Characterization of Nanohybrid C@HSA-MNPs@rGO}

For the synthesis of the nanohybrid C@HSA-MNPs@rGO, 45 mg C@HSA were added to $2.5 \mathrm{~mL}$ of MNPs@GO suspension synthesized by mixing 0.2 mL MNPs and 5.0 mg GO [39], and the resulting solution was stirred at $37^{\circ} \mathrm{C}$ for $12 \mathrm{~h}$. The nanohybrids were recovered as dark powder after freeze-drying process (Micro Modulyo, Edwards Lifesciences, Irvine, CA, USA).

Control nanoconjugates and nanocarriers were prepared in the same conditions employing HSA instead of C@HSA (HSA-MNPs@GO) or in the absence of MNPs (C@HSA-rGO and HSA-GO).

Scanning electron microscopy (SEM) images were obtained using a NOVA NanoSEM 200 (Thermo Fisher Scientific, Hillsboro, OR, USA) with an acceleration voltage of $15 \mathrm{kV}$ after depositing samples onto self-adhesive conducting carbon tape (Plano GmbH, Wetzlar, Germany).

Thermogravimetric analysis (TGA) was performed with an SDT Q600 (TA Instruments, Wetzlar, Germany). Measurements were conducted in a nitrogen atmosphere (flow of $10 \mathrm{~mL} \mathrm{~min}^{-1}$ ), with an initial sample weight of $\sim 10 \mathrm{mg}$ in the temperature range $25-600{ }^{\circ} \mathrm{C}$ at a heating rate of $10^{\circ} \mathrm{C} \mathrm{min}-1$.

The magnetization curves as a function of field and temperature were obtained using a commercial Superconducting Quantum Interference Device (SQUID, model MPMS by Quantum Design, Inc., San Diego, CA, USA). Measurements were performed within the $5 \leq T \leq 300 \mathrm{~K}$ temperature range, and applied magnetic fields up to $H=3989 \mathrm{kA} / \mathrm{m}$ (5 Tesla).

\subsection{In Vitro Releasing Tests}

Here, 0.5 mg DOX were stirred with 50 mg C@HSA-MNPs@rGO, HSA-MNPs@GO, and C@HSA-rGO in $5.0 \mathrm{~mL}$ distilled water for $24 \mathrm{~h}$ and then the loaded nanohybrids recovered after drying under vacuum. The release experiments were performed in phosphate buffered saline $\left(10^{-3} \mathrm{~mol} \mathrm{~L}^{-1}\right)$ at $\mathrm{pH} 7.4$ or 5.0. Briefly, $15.0 \mathrm{mg}$ loaded nanohybrid was dispersed into $1.5 \mathrm{~mL}$ phosphate buffered saline at selected $\mathrm{pH}$ into a dialysis bag (MWCO: 12,000-14,000 Da), and dialyzed against $13.5 \mathrm{~mL}$ of the corresponding buffer. At predetermined time intervals, the amount of DOX in the releasing media was determined by UV-Vis on a Jasco V-530 UV/Vis spectrometer (Jasco Europe s.r.l., Milan, Italy) at $496 \mathrm{~nm}$. From the calibration curves of DOX sketched in PBS (pH 7.4 and pH 5.0, respectively), the cumulative amount of drug released was calculated using Equation (2):

$$
\frac{M_{t}}{M_{0}}=\frac{M_{t}}{M_{\text {total }}}
$$

where $M_{t}$ and $M_{0}$ are the amounts of drug in solution at time $t$ and loaded into the carrier, respectively.

\subsection{Cell Viability Assay}

Human neuroblastoma SH-SY5Y (ATCC $® C R L-2266^{\mathrm{TM}}$ ) cells were employed to assess the cytotoxicity effect. Cells were grown in DMEM medium supplemented with $1 \%$ L-glutamine and $10 \%$ fetal bovine serum, routinely maintained in culture at $37^{\circ} \mathrm{C}$ and $5 \% \mathrm{CO}_{2}$ and regularly screened to ensure the absence of mycoplasma contamination using the MycoAlert MycoPlasma Detection Kit (Lonza, Switzerland). 
For cytotoxic experiments, cells were plated in clear transparent 96-well plates at optimized cell densities of $10^{4}$ cells per well. To ensure cell attachment, cells were seeded $24 \mathrm{~h}$ before being treated. Cells were treated with free DOX and DOX loaded nanohybrids for $72 \mathrm{~h}$. To determine the effect of the treatments on the cell viability, we counted the viable cell by using the Trypan Blue exclusion method as previously described [40]. All the cell viability assays have been conducted in the presence of $10 \%$ serum.

Finally, to evaluate the possibility to spatially control the DOX activity, viability experiments were performed by treating $250 \times 10^{3}$ cells seeded in a 35-mm petri dish with DOX loaded on either C@HSA-MNPs@rGO (DOX-C@HSA-MNPs@rGO) or C@HSA-rGO (DOX-C@HSA-rGO) for 72 h under the effect of a magnetic field generated by a permanent magnet (100 G).

\subsection{Cell Internalization Studies}

To prepare the samples for TEM analysis, the human neuroblastoma cells SH-SY5Y were seeded and incubated with C@HSA-MNPs@rGO. Cell internalizations study was carried out after 6 and $24 \mathrm{~h}$. After co-incubation, the medium was removed and the cells were detached and fixed with $2 \%$ glutaraldehyde solution at $4{ }^{\circ} \mathrm{C}$. After washing, cells were dehydrated with increasing concentrations of acetone and embedded in a solution (50:50) of epoxy resin. Then the EPOXI resin was cut in 70-nm thin slices. The samples were analyzed by transmission electron microscopy (TEM) using a FEI Tecnai T20 microscope operating at $200 \mathrm{keV}$.

\subsection{Statistical Analysis}

Three experiments were carried out in triplicate. Values were expressed as means \pm standard error of the mean (SEM). For viability assay, statistical significance was assessed by one-way analysis of variance followed by post-hoc comparison test (Tukey's test). Significance was set at $p<0.01$.

\section{Results}

The multifunctional nanohybrid described here is composed of C@HSA conjugate, GO, and MNPs, each addressing a specific requirement to develop a cancer therapy that could efficiently deliver DOX to neuroblastoma SH-SY5Y cells (Figure 1).

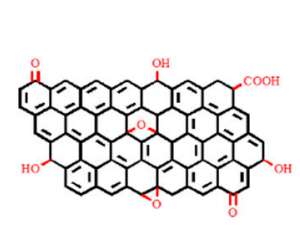

GO

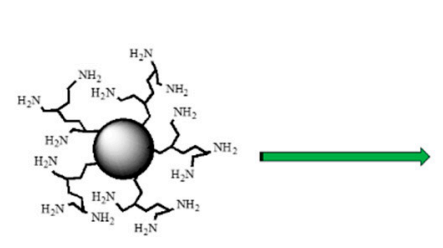

MNPs
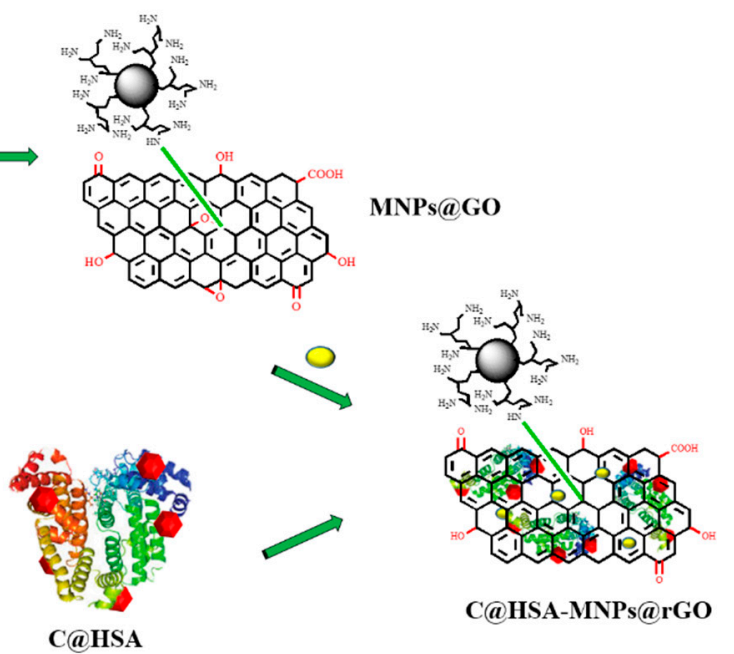

HSA

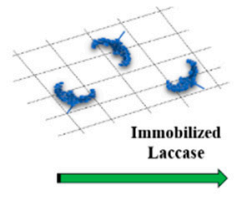

C@HSA
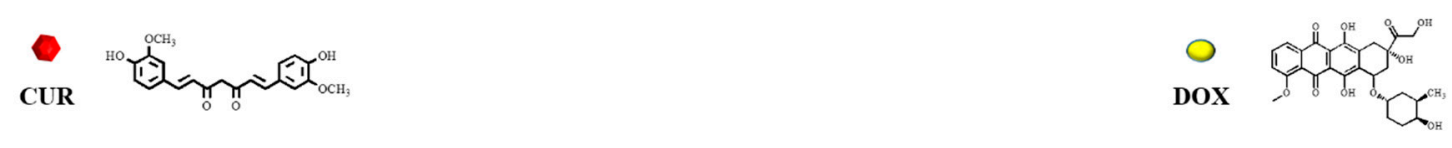

Figure 1. Schematic representation of the synthesis of nanohybrid C@HSA-MNPs@rGO. 
The synthetic procedure involved at first the synthesis of the inorganic (MNPs@GO) and organic counterparts (C@HSA), and subsequently their coupling for the obtainment of the nanohybrid C@HSA-MNPs@rGO.

The MNPs@GO system obtained via GO functionalization with polyethyleneimine polymer (PEI)-coated magnetic nanoparticles (PEI-MNPs) exploited the ability of PEI to covalently react with GO sheets via a "grafting to" process to produce highly stable nanohybrids [39]. For this purpose, MNPs were synthesized by a previously reported procedure [19] based on the oxidation of $\mathrm{Fe}(\mathrm{OH})_{2}$ by nitrate in basic aqueous media in the presence of branched PEI ( $25 \mathrm{kDa})$. By using this approach, we obtained PEI-MNPs with an average particle size of $25 \pm 5 \mathrm{~nm}$, composed of a thin layer (7-9 $)$ ) of PEI coating around the $\mathrm{Fe}_{3} \mathrm{O}_{4}$ core, showing high stability to aggregation, and the presence of functional groups on the particle surface suitable for further modification [35]. Then, the MNPs@GO system was obtained by mixing GO (average size of $100 \mathrm{~nm}$ ), synthesized by a modified Hummer's method [34], with PEI-MNPs under vigorous stirring at room temperature.

The FTIR spectrum of MNPs@GO (Figure 2) showed the retention of the typical GO peaks at 3440 (O-H stretching), 1725 (stretching $\mathrm{COOH}$ ), and 1625 (stretching $\mathrm{C}=\mathrm{C}$ ) $\mathrm{cm}^{-1}$, with the disappearance of the stretching peak of epoxy $\mathrm{C}-\mathrm{O}$ groups located at $1225 \mathrm{~cm}^{-1}$ invoked as a confirmation of the successful formation of MNPs@GO system due to the reaction with the amine groups of PEI. The presence of MNPs on GO surface was further confirmed by the increase in the intensity of the band located at around $3400 \mathrm{~cm}^{-1}$, which can be mainly ascribed to the $\mathrm{N}-\mathrm{H}$ stretch vibration of PEI, and $\mathrm{O}-\mathrm{H}$ stretching of water molecules bound to MNPs.

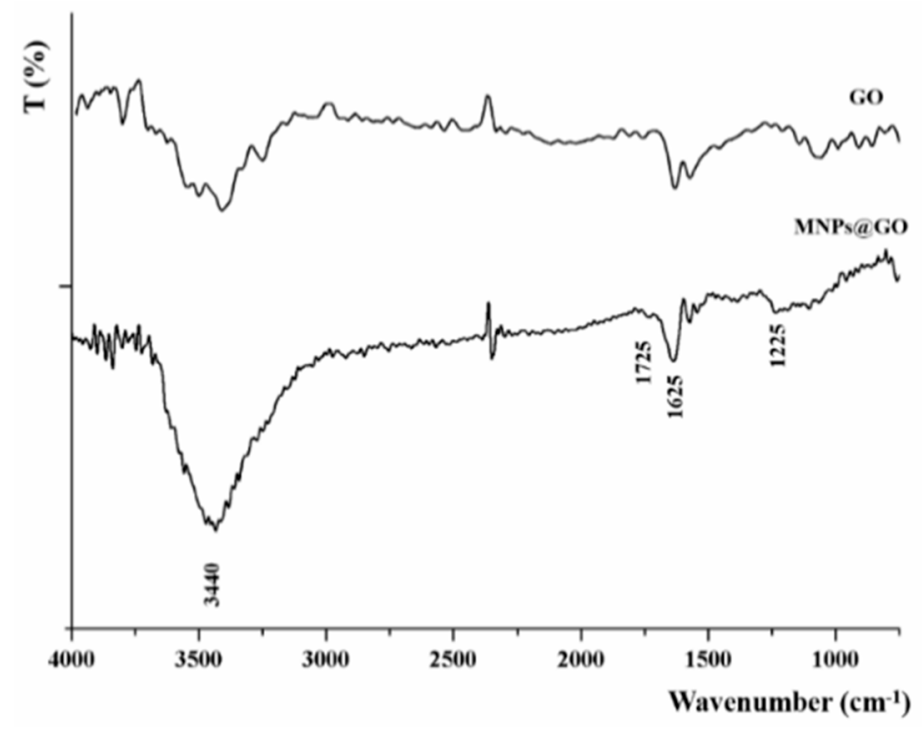

Figure 2. FTIR spectra of GO and MNPs@GO.

It is well known that for the preparation of effective nanocarriers, a surface modification of GO sheets is required to overcome their tendency to aggregate in physiological environment [15]; for this purpose different types of polymeric materials have been proposed as coating element [41]. Here, we coated MNPs@GO with a C@HSA conjugate to take advantage of the excellent biocompatibility and non-immunogenicity of HSA [42,43], and the biological activity of curcumin, a naturally occurring polyphenol with pronounced anticancer activity [17], with the aim to fabricate a functional nanohybrid (C@HSA-MNPs@rGO), in which the anticancer activity is related to both the controlled release of loaded drug and the carrier itself [29]. The covalent conjugation of CUR to HSA improved its stability within the physiological compartments [44]. This is a quite important point considering that improved aqueous solubility and stability of CUR are essential for its potential clinical application [45]. Furthermore, it is important to note that the CUR dose remain unmodified during the vectorization process, since no CUR delivery occurred within $24 \mathrm{~h}$ (data not shown). 
The C@HSA conjugate was synthesized via a fully green process involving the use of a solid biocatalyst previously developed and characterized and consisting of laccase immobilized into acrylate hydrogel film with a functionalization degree of $91 \mathrm{mg}$ of CUR per gram of conjugate, as per combined UV-VIS analysis and TNBS assay. Moreover, the hypsochromic shift recorded comparing the UV-VIS spectra of C@HSA and CUR from 420 to $347 \mathrm{~nm}$ was used as a confirmation of the covalent conjugation of the polyphenols to the protein backbone [46]. The reaction mechanism for the coupling of nanocarrier MNPs@GO with nanoconjugate C@HSA consisted of a redox reaction between the organic and inorganic counterparts, where the polyphenol moieties were converted to the corresponding oxidized quinone forms with adequate potential to reduce the oxygen-rich functionalities of GO, obtaining a reduced graphene oxide (rGO) nanohybrid (C@HSA-MNPs@rGO) [47-50]. The effective formation of nanohybrid C@HSA-MNPs@rGO was verified by SEM investigation (Figure 3a,b), where it is clear that the rGO nanosheets were homogeneously coated by the protein film.

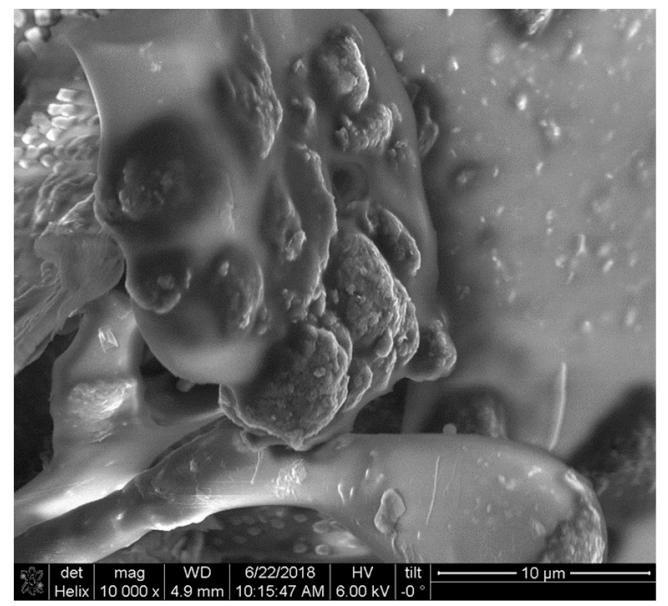

(a)

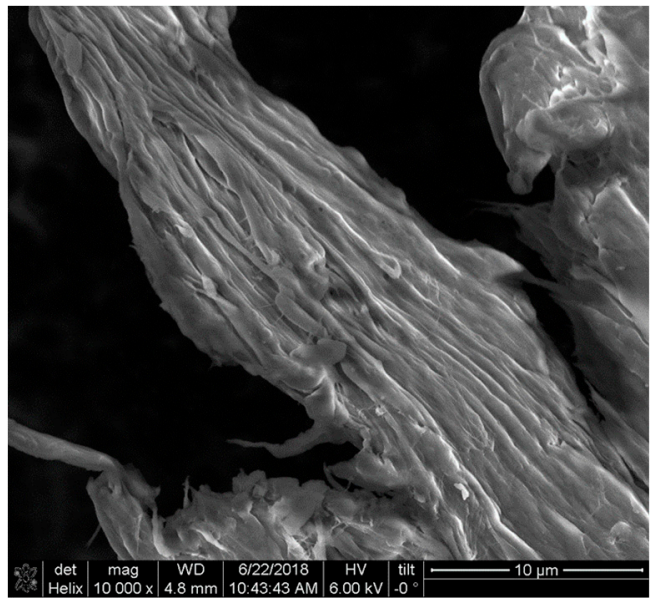

(b)

Figure 3. SEM pictures of nanohybrid C@HSA-MNPs@rGO.

The magnetic response of the nanohybrids was explored by $\mathrm{M}(\mathrm{T})$ and $\mathrm{M}(\mathrm{H})$ data (Figure 4).

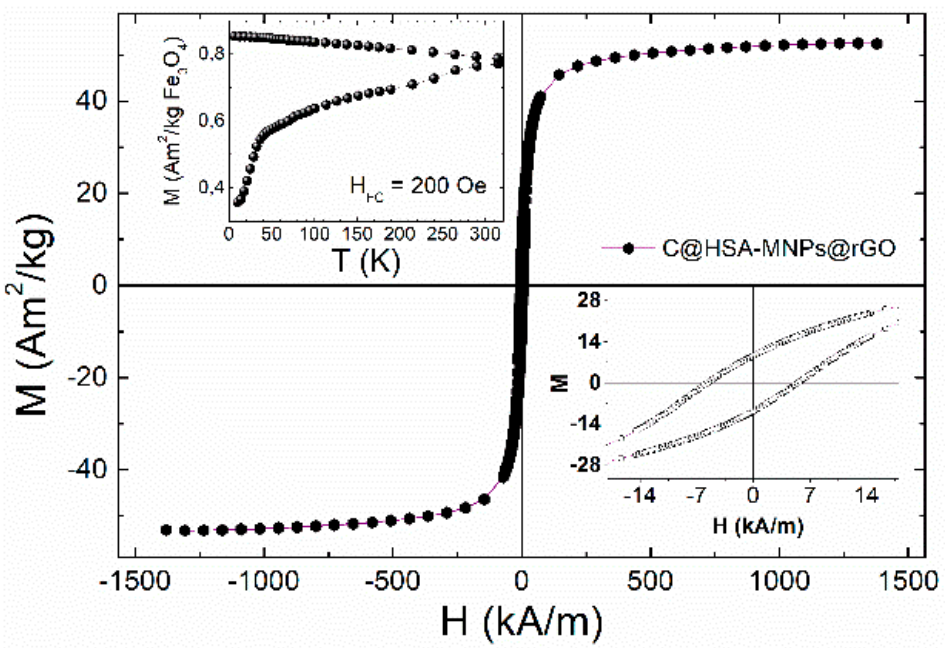

Figure 4. Main panel: Magnetization M data vs. applied field $H$ of nanohybrid C@HSA-MNPs@rGO at room temperature. Upper left panel: Zero-field-cooled and field-cooled $\mathrm{M}(\mathrm{T})$ curves at applied field $H=15.92 \mathrm{kA} / \mathrm{m}$. Low-right panel: Magnification of the low-field region of the $\mathrm{M}(\mathrm{H})$ hysteresis loop, showing the measurable coercive field at $T=295 \mathrm{~K}$ as a reflect of the blocked state of the magnetic nanoparticles within the nanohybrid. 
The temperature dependence $\mathrm{M}(\mathrm{T})$ using zero-field-cooling and field-cooling protocols showed no maximum in the ZFC curves corresponding to a blocking temperature, as expected due to the fact that single-domain magnetic cores of magnetite have an average size of over $40 \mathrm{~nm}$ (as observed in TEM images, see later). These $\mathrm{Fe}_{3} \mathrm{O}_{4}$ nanoparticles are expected to be blocked [51,52], given their size and value of magnetocrystalline anisotropy that yield an anisotropy relaxation energy barrier larger than thermal energy at room temperature. The hysteresis loops at room temperature showed saturation magnetization values $\left(M_{\mathrm{S}}\right)=48-52 \mathrm{Am}^{2} / \mathrm{kg}$, somewhat lower than the bulk $\mathrm{Fe}_{3} \mathrm{O}_{4}$. The observed lowering of the Ms when compared to the bulk values of $80-85 \mathrm{Am}^{2} / \mathrm{kg}$ is related to a low crystallinity of the MNPs that in turn is probably originated in the low temperature of the hydrothermal route used in this work [35,53]. The existence of a coercive field of $H_{C}=5.82 \mathrm{kA} / \mathrm{m}$ at room temperature supported the hypothesis that these magnetic cores are magnetically blocked.

TGA analyses (Figure 5a) were performed to check the thermal stability of the final nanohybrids. At first, HSA-GO was employed as control sample, and the effect of each component was highlighted by measuring C@HSA-rGO and C@HSA-MNPs@rGO. The presence of CUR residues was found to enhance the thermal stability of C@HSA-rGO [54], with a lower degradation (73\% vs. 77\%) recorded at $600{ }^{\circ} \mathrm{C}$ (Figure 5a). On the other hand, the higher amount of organic counterpart (PEI coating of PEI-MNPs) resulted in a lower thermal stability of C@HSA-MNPs@rGO (degradation of 80\%). The same trend was recorded when considering the weight loss at the degradation temperature, located at around $310{ }^{\circ} \mathrm{C}$ for all samples (see the derivative thermogravimetric analysis, DTG curve, Figure $5 \mathrm{~b}$ ), with the degradation values of 38 (HSA-GO), 33 (C@HSA-rGO), and 40\% (C@HSA-MNPs@rGO).

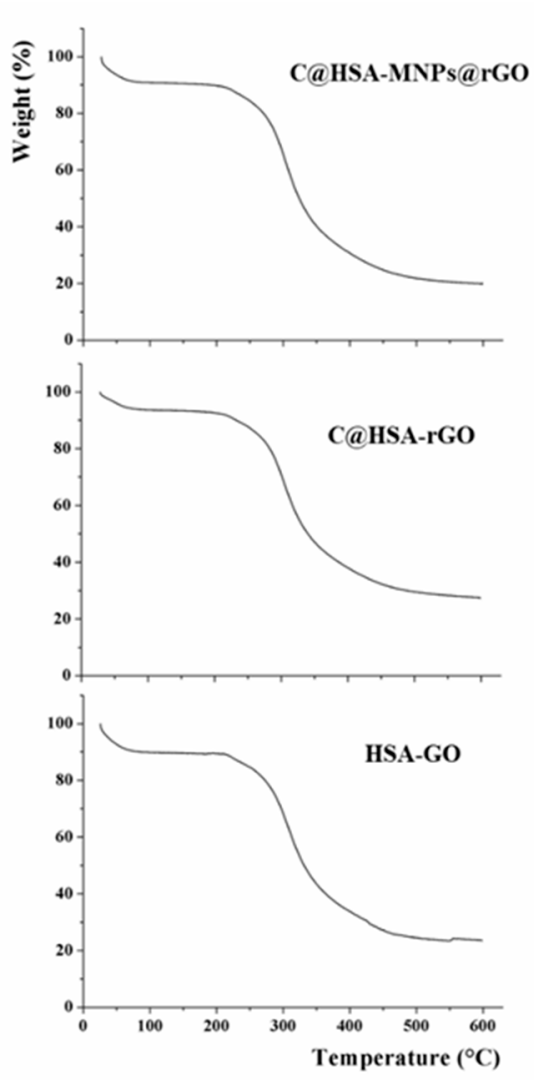

(a)

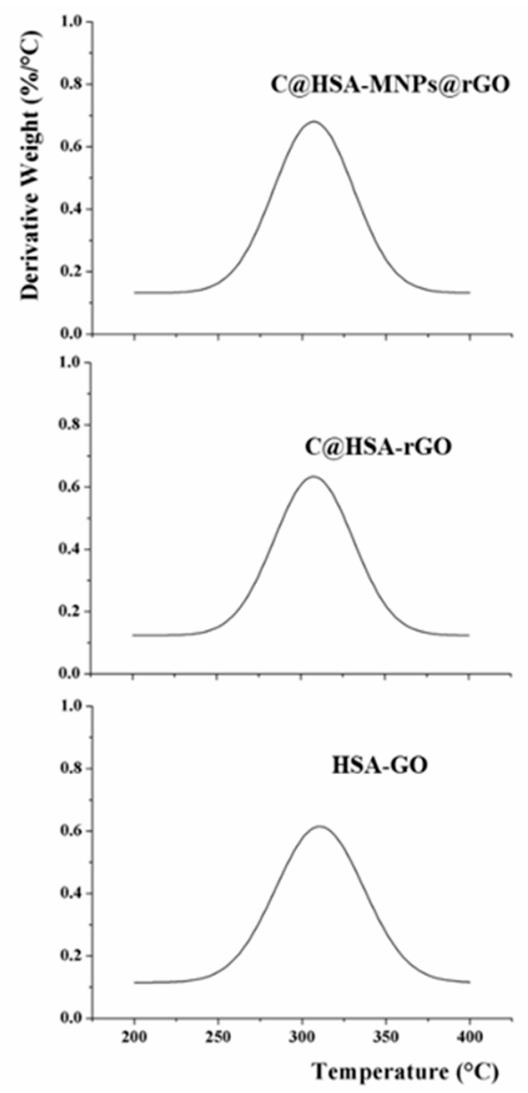

(b)

Figure 5. TGA (a) and DTG (b) curves of C@HSA-rGO, HSA-GO, and C@HSA-MNPs@rGO.

\subsection{In Vitro Doxorubicin Release}

The nanohybrid C@HSA-MNPs@rGO was designed as DOX delivery vehicle, employing a drug to $\mathrm{rGO}$ ratio (by weight) of $12.5 \%$. Release experiments were performed at $\mathrm{pH} 5.5$ and 7.4 , simulating 
the endosomal $\mathrm{pH}$ of cancer cells and the normal physiological $\mathrm{pH}$, respectively [55], and, to highlight the importance of rGO within the nanocarrier, the results were compared with those obtained when C@HSA-MNPs, not containing rGO, were employed (Figure 6).

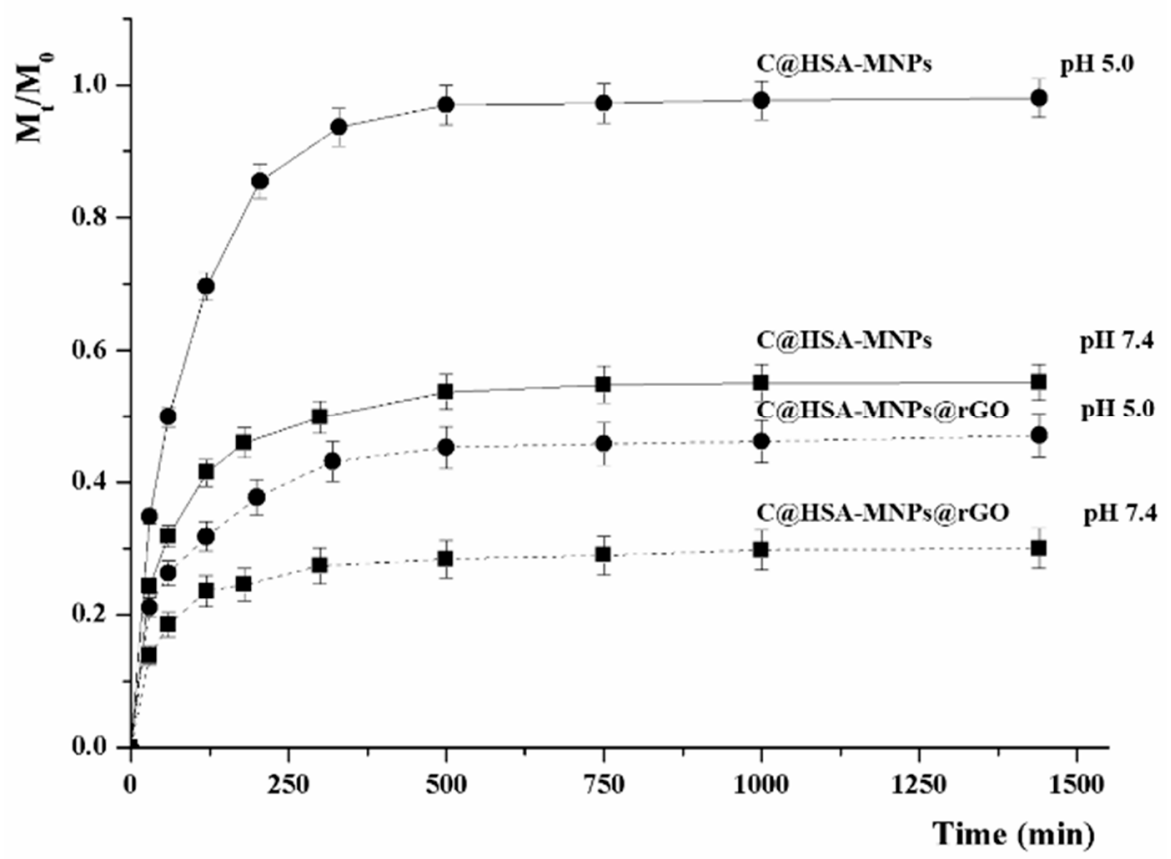

Figure 6. $\mathrm{pH}$-responsive DOX release profile (Mt/M0) from C@HSA-MNPs (solid line) and C@HSA-MNPs@rGO (dashed lines) at pH $5.0(\bullet)$ and $7.4(\boldsymbol{\square})$.

Assuming that the amount of DOX in the release media is a result of the partition between the carrier and the surrounding environments, the application of a mathematical modelling proposed in literature allowed the determination of key parameters describing this phenomenon according to reversible first- and second-order kinetics (Equations (3) and (4)) [56]:

$$
\begin{aligned}
& \frac{M_{t}}{M_{0}}=F_{\max }\left(1-e^{-\left(\frac{k_{R}}{F_{\max }}\right) t}\right) \\
& \frac{M_{t}}{M_{0}}=\frac{F_{\max }\left(e^{2\left(\frac{k_{R}}{\alpha}\right) t}-1\right)}{1-2 F_{\max }+e^{2\left(\frac{k_{R}}{\alpha}\right) t}}
\end{aligned}
$$

$F_{\text {max }}$ is the maximum value of relative release $\left(M_{t} / M_{0}\right), k_{R}$ the release rate constant, while the physicochemical affinity of the drug between the carrier and solvent phases $(\alpha)$ can be determined according to the following Equation (5):

$$
\alpha=\frac{F_{\max }}{1-F_{\max }}
$$

Both Equations (3) and (4) can be used to calculate the time required for reaching $50 \%$ of $F_{\max }\left(t_{1 / 2}^{R}\right)$ (Equations (6) and (7)), respectively:

$$
\begin{gathered}
t_{1 / 2}^{R^{1}}=\frac{F_{\max }}{k_{R}} \ln 2 \\
t_{1 / 2}^{R^{2}}=\frac{\alpha}{2 k R} \ln \left(3-2 F_{\max }\right)
\end{gathered}
$$

The experimental data were well fitted by either Equation (3) or $(4)\left(R^{2}>0.95\right.$, Table 1), with predominant reversible first-order kinetics. 
Table 1. $\mathrm{R}^{2}$ values and kinetic parameters.

\begin{tabular}{|c|c|c|c|c|c|}
\hline \multirow{3}{*}{ Mathematical Model } & \multirow{3}{*}{ Parameter } & \multicolumn{2}{|c|}{ C@HSA-MNPs } & \multicolumn{2}{|c|}{ C@HSA-MNPs@rGO } \\
\hline & & \multicolumn{4}{|c|}{$\mathrm{pH}$} \\
\hline & & 2.0 & 7.0 & 2.0 & 7.0 \\
\hline \multirow{5}{*}{$\frac{M_{t}}{M_{0}}=F_{\max }\left(1-e^{-\left(k_{R} / M_{\max }\right) t}\right)$} & $R^{2}$ & 0.9935 & 0.9747 & 0.9563 & 0.9731 \\
\hline & $F \max$ & 0.97 & 0.53 & 0.45 & 0.28 \\
\hline & $\alpha$ & 32.33 & 1.13 & 0.82 & 0.39 \\
\hline & $k_{\mathrm{R}}\left(10^{-2}\right)$ & 1.13 & 0.79 & 0.60 & 0.50 \\
\hline & $t_{1 / 2}^{R^{1}}(\min )$ & 60 & 47 & 52 & 39 \\
\hline \multirow{5}{*}{$\frac{M_{t}}{M_{0}}=\frac{F_{\max }\left(e^{2\left(\frac{k_{R}}{\alpha}\right) t}-1\right)}{1-2 F_{\max }+e^{2\left(\frac{k_{R}}{\alpha}\right) t}}$} & $R^{2}$ & 0.9717 & 0.9765 & 0.9527 & 0.9639 \\
\hline & Fmax & 0.98 & 0.53 & 0.45 & 0.28 \\
\hline & $\alpha$ & 49.00 & 1.13 & 0.82 & 0.39 \\
\hline & $k_{\mathrm{R}}\left(10^{-2}\right)$ & 1.87 & 0.81 & 0.58 & 0.44 \\
\hline & $t_{1 / 2}^{R^{2}}(\min )$ & 52 & 46 & 52 & 39 \\
\hline \multirow{4}{*}{$\frac{M_{t}}{M_{0}}=1-e^{-k t^{n}}$} & $R^{2}$ & 0.9946 & 0.9933 & 0.9888 & 0.9248 \\
\hline & $K\left(10^{-2}\right)$ & 2.90 & 8.46 & 7.28 & 6.14 \\
\hline & $n$ & 0.78 & 0.37 & 0.35 & 0.29 \\
\hline & $t_{1 / 2}^{A}(\min )$ & 58 & 294 & $\#$ & \# \\
\hline
\end{tabular}

Figure 6 clearly showed $\mathrm{pH}$-sensitive behavior, with the reduction of $\mathrm{pH}$ values carrying out to higher amount of released drug ( $F_{\max }$ of $45 \%$ and $28 \%$ at pH 5.5 and 7.4 , respectively, see Table 1 ). Compared to physiological environments, at lower $\mathrm{pH}$ value, indeed an easier DOX protonation occurred, with a reduction of the hydrophobic-driven interactions between drug and carrier $(\alpha$ moved from 0.39 to 0.82 ), somehow fastening the DOX dissolution $\left(k_{\mathrm{R}}\right.$ increases from 0.50 to 0.60 and $t_{1 / 2}^{R}$ decreases from 52 to $39 \mathrm{~min}$ ). However, at both $\mathrm{pH}$ values, the amount of DOX in the surrounding environments was always lower than $50 \%$, highlighting the strong ability of rGO to load and carry drug molecules with high affinity [57]. The low DOX release at physiological $\mathrm{pH}$ is expected to dramatically reduce the drug side effects, thus enhancing the therapeutic index. This result underlines the importance of rGO into the nanocarrier, with C@HSA-MNPs showing a lower drug to carrier affinity (highest $\alpha$ values at both $\mathrm{pH}$ ), with $53 \%$ of DOX released at $\mathrm{pH} 7.4$, increasing up to $97 \%$ at acidic $\mathrm{pH}$.

More detailed information about the release mechanisms can be obtained by applying the mathematical model proposed by Avrami (Equation (8)) [58], fitting well with the experimental data $\left(R^{2}\right.$ values $\left.>0.92\right)$ :

$$
\frac{M_{t}}{M_{0}}=1-e^{-k t^{n}}
$$

$n$ and $k$ are the Avrami parameter and release rate constant, respectively and were calculated by rewriting of Equation (8) by double logarithm (Equation (9)) and plotting of $\ln (\ln (1-X))$ vs. $\ln t$.

$$
\ln \left(-\ln \left(1-\frac{M_{t}}{M_{0}}\right)\right)=\ln k+n \ln t
$$

The recorded $n$ values for C@HSA-MNPs@rGO (Table 1) allowed for hypothesizing that the release kinetics were mainly diffusive ( $n$ close to 0.54 ). Interestingly, the carrier prepared in the absence of rGO (C@HSA-MNPs) showed a similar behavior at pH 7.4, while under acidic conditions a first-order kinetic was invoked to explain the higher DOX release.

The effect of $\mathrm{rGO}$ and $\mathrm{pH}$ on the releasing rate was better highlighted by the introduction of the half-life release time obtained when $M_{t} / M_{0}$ is $0.5\left(t_{1 / 2}\right)$, according to Equation (10). 


$$
t_{1 / 2}=e^{\left(\frac{-\ln k-0.367}{n}\right)}
$$

The model reflected the experimental fact that, in the absence of rGO, faster release was detected in acidic $\left(t_{1 / 2}\right.$ of around $\left.60 \mathrm{~min}\right)$ compared to neutral $\left(t_{1 / 2}\right.$ of around $\left.290 \mathrm{~min}\right)$ conditions, while the presence of GO dramatically slowed the release and the $t_{1 / 2}$ values were found to be outside of the experimental range of $24 \mathrm{~h}$. Finally, for both models, it should be pointed out that the presence of CUR did not significantly interfere with the release kinetics $(p>0.05)$, with the release profiles of HSA-MNPs and HSA-MNPs@GO being closer to C@HSA-MNPs and C@HSA-MNPs@rGO, respectively (data not shown).

\subsection{Evaluation of Cytotoxic Activity}

The cytotoxic activity of DOX after loading into C@HSA-MNPs@rGO nanohybrids (DOX to carrier ratio of $12.5 \%$ by weight) was tested on neuroblastoma SH-SY5Y cells (Figure 7). As a control sample, we employ DOX-loaded HSA-MNPs@GO to highlight the effect of the functional coating on the nanohybrid structure.

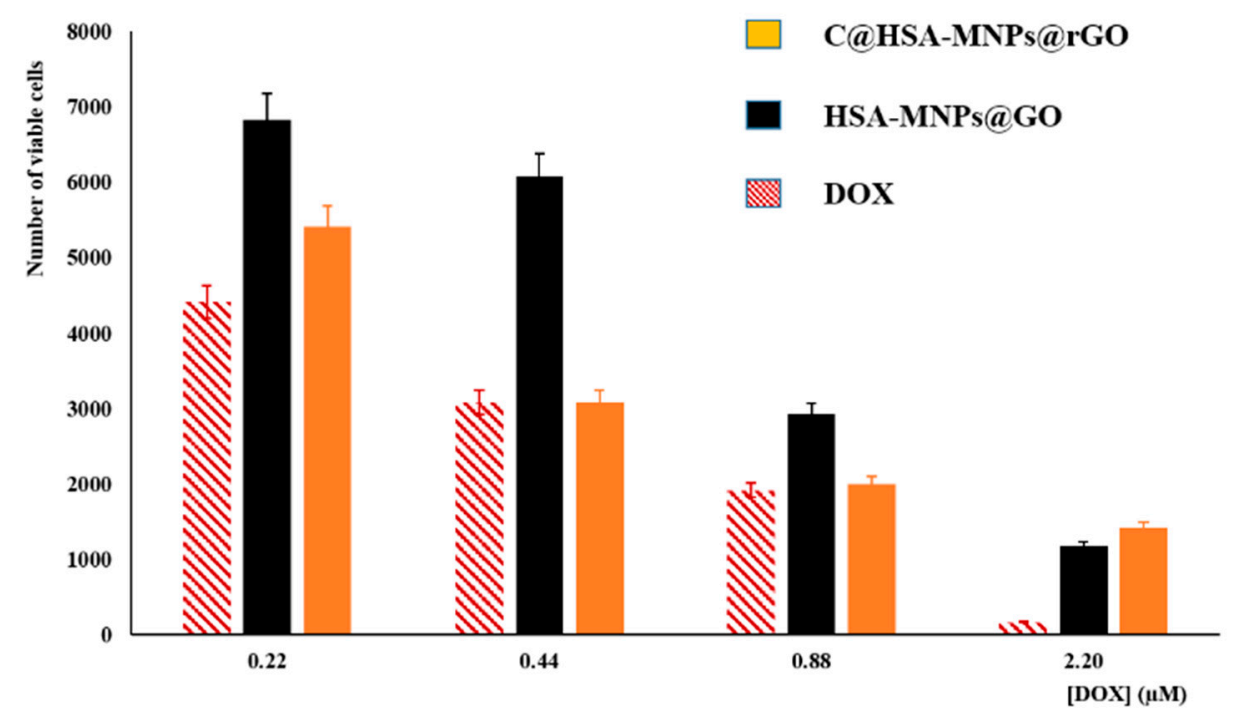

Figure 7. SH-SY5Y viability after treatment with free and loaded DOX on HSA-MNPs@GO and C@HSA-MNPs@rGO.

At first, free drug was tested in the range of $0.22-2.20 \mu \mathrm{M}$, showing a typical dose-dependent response. Then, empty carriers showed no toxicity in the tested concentrations $\left(10.2\right.$ to $\left.102 \mu \mathrm{gL}^{-1}\right)$, with cell viability values (\%) higher than $95 \%$ in all cases (data not shown).

Performing the viability assays with loaded systems at equivalent DOX concentrations, the effect of the nanohybrid was evident. The high affinity of GO for the anticancer therapeutic resulted in a significant reduction of the cytotoxic effect when HSA-MNPs@GO was employed as carrier. This is in accordance with the literature data proving that a slower release of DOX from nanoparticule delivery system is associated with a reduction of toxicity of loaded vs. free DOX at equivalent concentrations [59-62]. While free DOX penetrated the cell membrane through passive diffusion, comparatively long time was required for loaded DOX due to strong $\pi-\pi$ stacking and endocytosis-mediated cytosolic sustained release [63-65]. In our experimental conditions, the ability of nanohybrid to cross the cell membrane is proved by TEM analysis (Figure 8), showing the presence of nanohybrids within the cytoplasm of SH-SY5Y cells. 


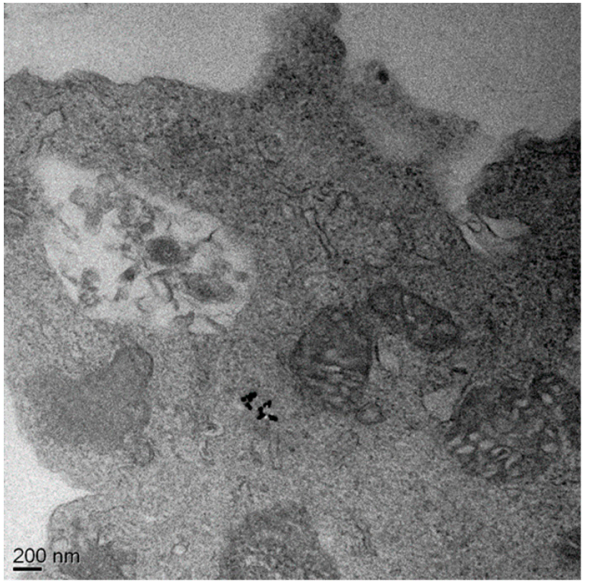

(a)

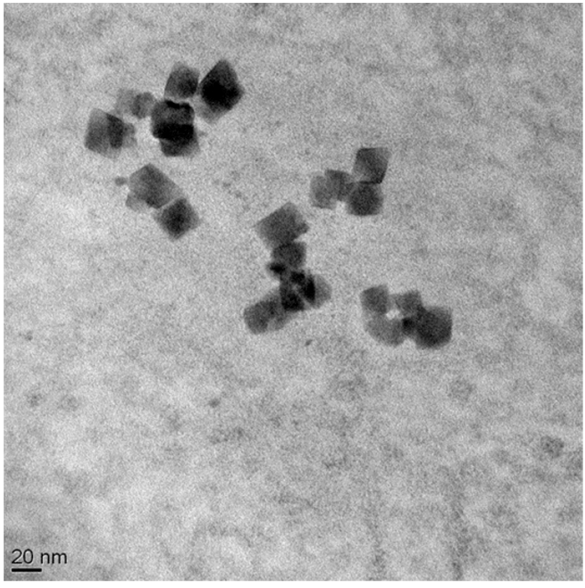

(b)

Figure 8. TEM images of SH-SY5Y after incubation with C@HSA-MNPs@rGO, proving the presence of nanohybrid within the cytoplasm.

To further improve the therapeutic outcome, we performed additional experiments employing similar carriers but functionalized with CUR (C@HSA-MNPs@rGO). In these experiments the well-known synergistic activity between the polyphenol species and DOX [66] enhanced the activity of the released drug, with the cytotoxicity becoming similar to the free DOX at 0.44 and $0.88 \mu \mathrm{M}$ (Figure 7). The maintenance of the DOX anticancer efficiency, combined with both the selective release capability in acidic conditions and the magnetic properties, makes the proposed C@HSA-MNPs@rGO nanohybrid a promising carrier for a targeted therapy. It can be hypothesized that the carrier is able to spatially control the DOX anticancer activity being selectively attracted from a magnetic field. To confirm this finding, we incubated $250 \times 10^{3}$ cells seeded in a $35-\mathrm{mm}$ petri dish with DOX loaded on either C@HSA-MNPs@rGO or C@HSA-rGO for $72 \mathrm{~h}$ under the effect of a magnetic field generated by a permanent Nd-Fe-B magnet. For DOX-C@HSA-MNPs@rGO, the results showed a clear targeted cell death at the region close to the magnet, as a consequence of the increased local concentration of the drug by MNPs. Concurrently, no relevant toxicity was observed on the opposite region of the petri dish, where the magnetic forces were negligible (Figure 9a). The same experiment was performed with DOX-C@HSA-rGO as a control for the magnetic field effects, since the absence of the MNPs makes the compound not responsive to the magnetic field, which results in absence of any spatial control of the drug activity (Figure 9b).

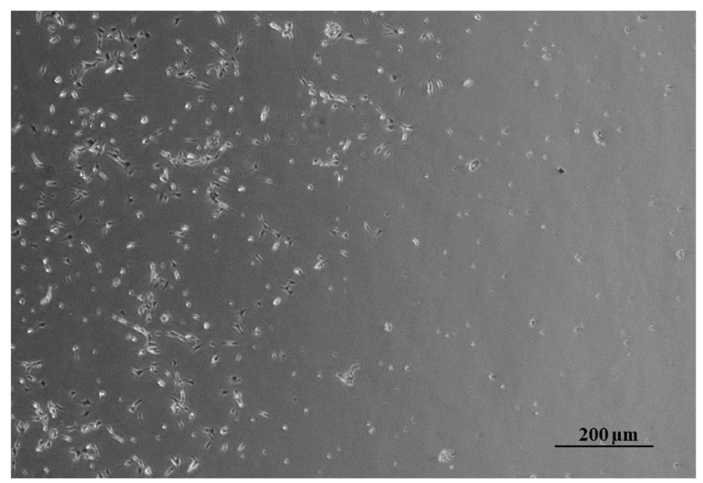

(a)

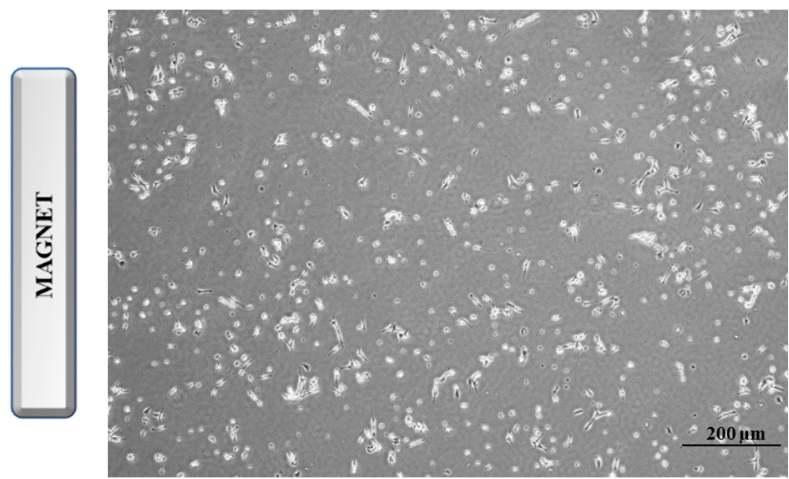

(b)

Figure 9. Optical microscope image SH-SY5Y incubated with DOX-C@HSA-MNPs@rGO (a) and DOX-C@HSA-rGO (b) under the effect of a permanent magnet. 
Our results have proved the potential applicability of DOX-C@HSA-MNPs@rGO in the vectorization of DOX to neuroblastoma cells due to their capability to be selectively attracted from a magnetic field. These nanoparticles can potentially accumulate in tumors as a consequence of the enhanced permeability and retention (EPR) effect, and enable preferential drug release in response to the decreased tissue $\mathrm{pH}$ of either the extracellular (e.g., hypoxia) or intracellular (e.g., endosomes) tumor compartments [67]. Future experiments will be performed for evaluating the pharmacokinetics profiles with or without magnetic field, the anticancer activity, and the theranostics (e.g., MRI imaging) properties of the nanohybrid in suitable orthotopic neuroblastoma xenograft models.

\section{Conclusions}

We presented experimental evidence that the novel C@HSA-MNPs@rGO is a capable nanoplatform to provide spatial control for the release of cytotoxic agents such as DOX, due to the combined unique features of GO, MNPs, and C@HSA conjugates. While GO was responsible for the observed high loading capacity, the MNPs provided remote-actuation capabilities to deliver the nanohybrids to specific target sites. Moreover, the C@HSA conjugate coating acted synergistically with the DOX to increase the therapeutic effects on cancer cells.

The synthetic strategy consisted in two steps: C@HSA and MNPs@GO were preliminary fabricated via enzyme catalysis and chemical coupling, respectively, and then assembled to form the final nanohybrid C@HSA-MNPs@rGO. The physico-chemical characterization of the nanohybrids regarding their morphological, thermal, and magnetic properties showed the correct assembly of the components as well as the magnetic responsiveness expected for a targeted delivery vehicle for DOX. The DOX release profile was found to be tunable by $\mathrm{pH}$, as a consequence of the modulation of the drug to carrier affinity, whereas the in vitro viability assays clearly showed the enhancement of cytotoxic activity due to the presence of CUR moieties within the nanohybrid coating. The observed levels of nanohybrid internalization by SH-SY5Y cells, together with magnetic actuation by external magnetic fields to increase local concentration at targeted sites, makes this nanohybrid a promising carrier for neuroblastoma treatment.

Author Contributions: Conceptualization, G.C. and O.V.; Formal analysis, O.V. and F.P.N.; Investigation, L.L., A.F., B.S., F.V., M.L.G., and M.C.; Methodology, G.C. and O.V.; Resources, A.D., S.H. and G.F.G.; Supervision, F.I. and G.F.G.; Validation, G.C. and F.P.N.; Visualization, O.V. and M.C.; Writing-original draft, G.C.; Writing-Review and Editing, F.P.N., A.D., S.H., F.I., and G.F.G.

Funding: This research received no external funding.

Conflicts of Interest: The authors declare no conflict of interest.

\section{References}

1. Ratner, N.; Brodeur, G.M.; Dale, R.C.; Schor, N.F. The "neuro" of neuroblastoma: Neuroblastoma as a neurodevelopmental disorder. Ann. Neurol. 2016, 80, 13-23. [CrossRef] [PubMed]

2. Pearson, A.D.; Pinkerton, C.R.; Lewis, I.J.; Imeson, J.; Ellershaw, C.; Machin, D. High-dose rapid and standard induction chemotherapy for patients aged over 1 year with stage 4 neuroblastoma: A randomised trial. Lancet Oncol. 2008, 9, 247-256. [CrossRef]

3. Sagnella, S.M.; Trieu, J.; Brahmbhatt, H.; MacDiarmid, J.A.; MacMillan, A.; Whan, R.M.; Fife, C.M.; McCarroll, J.A.; Gifford, A.J.; Ziegler, D.S.; et al. Targeted doxorubicin-loaded bacterially derived nano-cells for the treatment of neuroblastoma. Mol. Cancer Ther. 2018, 17, 1012-1023. [CrossRef] [PubMed]

4. Smith, M.A.; Altekruse, S.F.; Adamson, P.C.; Reaman, G.H.; Seibel, N.L. Declining childhood and adolescent cancer mortality. Cancer 2014, 120, 2497-2506. [CrossRef] [PubMed]

5. Fletcher, J.I.; Ziegler, D.S.; Trahair, T.N.; Marshall, G.M.; Haber, M.; Norris, M.D. Too many targets, not enough patients: Rethinking neuroblastoma clinical trials. Nat. Rev. Cancer 2018, 18, 389-400. [CrossRef] [PubMed]

6. Rodríguez-Nogales, C.; González-Fernández, Y.; Aldaz, A.; Couvreur, P.; Blanco-Prieto, M.J. Nanomedicines for Pediatric Cancers. ACS Nano 2018, 12, 7482-7496. [CrossRef] 
7. Kunz-Schughart, L.A.; Dubrovska, A.; Peitzsch, C.; Ewe, A.; Aigner, A.; Schellenburg, S.; Muders, M.H.; Hampel, S.; Cirillo, G.; Iemma, F.; et al. Nanoparticles for radiooncology: Mission, vision, challenges. Biomaterials 2017, 120, 155-184. [CrossRef]

8. Vittorio, O.; Voliani, V.; Faraci, P.; Karmakar, B.; Iemma, F.; Hampel, S.; Kavallaris, M.; Cirillo, G. Magnetic catechin-dextran conjugate as targeted therapeutic for pancreatic tumour cells. J. Drug Target. 2014, 22, 408-415. [CrossRef]

9. Xu, H.L.; Mao, K.L.; Huang, Y.P.; Yang, J.J.; Xu, J.; Chen, P.P.; Fan, Z.L.; Zou, S.; Gao, Z.Z.; Yin, J.Y.; et al. Glioma-targeted superparamagnetic iron oxide nanoparticles as drug-carrying vehicles for theranostic effects. Nanoscale 2016, 8, 14222-14236. [CrossRef]

10. Wahajuddin, S.A. Superparamagnetic iron oxide nanoparticles: Magnetic nanoplatforms as drug carriers. Int. J. Nanomed. 2012, 7, 3445-3471. [CrossRef]

11. Manju, S.; Sreenivasan, K. Enhanced drug loading on magnetic nanoparticles by layer-by-layer assembly using drug conjugates: Blood compatibility evaluation and targeted drug delivery in cancer cells. Langmuir 2011, 27, 14489-14496. [CrossRef]

12. Feng, L.; Liu, Z. Graphene in biomedicine: Opportunities and challenges. Nanomedicine 2011, 6, 317-324. [CrossRef] [PubMed]

13. Makharza, S.; Vittorio, O.; Cirillo, G.; Oswald, S.; Hinde, E.; Kavallaris, M.; Buechner, B.; Mertig, M.; Hampel, S. Graphene Oxide-Gelatin Nanohybrids as Functional Tools for Enhanced Carboplatin Activity in Neuroblastoma Cells. Pharm. Res. 2015, 32, 2132-2143. [CrossRef]

14. Byun, J. Emerging frontiers of graphene in biomedicine. J. Microbiol. Biotechnol. 2015, 25, 145-151. [CrossRef] [PubMed]

15. de Melo-Diogo, D.; Lima-Sousa, R.; Alves, C.G.; Costa, E.C.; Louro, R.O.; Correia, I.J. Functionalization of graphene family nanomaterials for application in cancer therapy. Colloids Surf. B Biointerfaces 2018, 171, 260-275. [CrossRef] [PubMed]

16. Vittorio, O.; Curcio, M.; Cojoc, M.; Goya, G.F.; Hampel, S.; Iemma, F.; Dubrovska, A.; Cirillo, G. Polyphenols delivery by polymeric materials: Challenges in cancer treatment. Drug Deliv. 2017, 24, 162-180. [CrossRef] [PubMed]

17. Picone, P.; Nuzzo, D.; Caruana, L.; Messina, E.; Scafidi, V.; Di Carlo, M. Curcumin induces apoptosis in human neuroblastoma cells via inhibition of AKT and Foxo3a nuclear translocation. Free Radic. Res. 2014, 48, 1397-1408. [CrossRef] [PubMed]

18. Yallapu, M.M.; Ebeling, M.C.; Khan, S.; Sundram, V.; Chauhan, N.; Gupta, B.K.; Puumala, S.E.; Jaggi, M.; Chauhan, S.C. Novel curcumin-loaded magnetic nanoparticles for pancreatic cancer treatment. Mol. Cancer Ther. 2013, 12, 1471-1480. [CrossRef]

19. Calatayud, M.P.; Sanz, B.; Raffa, V.; Riggio, C.; Ibarra, M.R.; Goya, G.F. The effect of surface charge of functionalized $\mathrm{Fe}_{3} \mathrm{O}_{4}$ nanoparticles on protein adsorption and cell uptake. Biomaterials 2014, 35, 6389-6399. [CrossRef]

20. Mojica Pisciotti, M.L.; Lima, E., Jr.; Vasquez Mansilla, M.; Tognoli, V.E.; Troiani, H.E.; Pasa, A.A.; Creczynski-Pasa, T.B.; Silva, A.H.; Gurman, P.; Colombo, L.; et al. In vitro and in vivo experiments with iron oxide nanoparticles functionalized with DEXTRAN or polyethylene glycol for medical applications: Magnetic targeting. J. Biomed. Mater. Res. Part B Appl. Biomater. 2014, 102, 860-868. [CrossRef]

21. Li, K.; Nejadnik, H.; Daldrup-Link, H.E. Next-generation superparamagnetic iron oxide nanoparticles for cancer theranostics. Drug Discov. Today 2017, 22, 1421-1429. [CrossRef] [PubMed]

22. Lu, Y.J.; Wei, K.C.; Ma, C.C.M.; Yang, S.Y.; Chen, J.P. Dual targeted delivery of doxorubicin to cancer cells using folate-conjugated magnetic multi-walled carbon nanotubes. Colloids Surf. B Biointerfaces 2012, 89, 1-9. [CrossRef] [PubMed]

23. Yang, K.; Feng, L.; Shi, X.; Liu, Z. Nano-graphene in biomedicine: Theranostic applications. Chem. Soc. Rev. 2013, 42, 530-547. [CrossRef] [PubMed]

24. Chung, C.; Kim, Y.K.; Shin, D.; Ryoo, S.R.; Hong, B.H.; Min, D.H. Biomedical applications of graphene and graphene oxide. Acc. Chem. Res. 2013, 46, 2211-2224. [CrossRef] [PubMed]

25. Shim, G.; Kim, M.G.; Park, J.Y.; Oh, Y.K. Graphene-based nanosheets for delivery of chemotherapeutics and biological drugs. Adv. Drug Deliv. Rev. 2016, 105, 205-227. [CrossRef] [PubMed]

26. Liu, J.; Cui, L.; Losic, D. Graphene and graphene oxide as new nanocarriers for drug delivery applications. Acta Biomater. 2013, 9, 9243-9257. [CrossRef] [PubMed] 
27. Liu, J.; Dong, J.; Zhang, T.; Peng, Q. Graphene-based nanomaterials and their potentials in advanced drug delivery and cancer therapy. J. Control. Release 2018, 286, 64-73. [CrossRef] [PubMed]

28. Vittorio, O.; Le Grand, M.; Makharza, S.A.; Curcio, M.; Tucci, P.; Iemma, F.; Nicoletta, F.P.; Hampel, S.; Cirillo, G. Doxorubicin synergism and resistance reversal in human neuroblastoma BE(2)C cell lines: An in vitro study with dextran-catechin nanohybrids. Eur. J. Pharm. Biopharm. 2018, 122, 176-185. [CrossRef]

29. Vittorio, O.; Brandl, M.; Cirillo, G.; Spizzirri, U.G.; Picci, N.; Kavallaris, M.; Iemma, F.; Hampel, S. Novel functional cisplatin carrier based on carbon nanotubes-quercetin nanohybrid induces synergistic anticancer activity against neuroblastoma in vitro. RSC Adv. 2014, 4, 31378-31384. [CrossRef]

30. Alshatwi, A.A.; Periasamy, V.S.; Athinarayanan, J.; Elango, R. Synergistic anticancer activity of dietary tea polyphenols and bleomycin hydrochloride in human cervical cancer cell: Caspase-dependent and independent apoptotic pathways. Chem. Biol. Interact. 2016, 247, 1-10. [CrossRef]

31. Aires, V.; Limagne, E.; Cotte, A.K.; Latruffe, N.; Ghiringhelli, F.; Delmas, D. Resveratrol metabolites inhibit human metastatic colon cancer cells progression and synergize with chemotherapeutic drugs to induce cell death. Mol. Nutr. Food Res. 2013, 57, 1170-1181. [CrossRef] [PubMed]

32. Torchilin, V.P. Multifunctional, stimuli-sensitive nanoparticulate systems for drug delivery. Nat. Rev. Drug Discov. 2014, 13, 813-827. [CrossRef] [PubMed]

33. Biju, V. Chemical modifications and bioconjugate reactions of nanomaterials for sensing, imaging, drug delivery and therapy. Chem. Soc. Rev. 2014, 43, 744-764. [CrossRef] [PubMed]

34. Makharza, S.; Cirillo, G.; Bachmatiuk, A.; Vittorio, O.; Mendes, R.G.; Oswald, S.; Hampel, S.; Ruemmeli, M.H. Size-dependent nanographene oxide as a platform for efficient carboplatin release. J. Mater. Chem. B 2013, 1, 6107-6114. [CrossRef]

35. Calatayud, M.P.; Riggio, C.; Raffa, V.; Sanz, B.; Torres, T.E.; Ibarra, M.R.; Hoskins, C.; Cuschieri, A.; Wang, L.; Pinkernelle, J.; et al. Neuronal cells loaded with PEI-coated $\mathrm{Fe}_{3} \mathrm{O}_{4}$ nanoparticles for magnetically guided nerve regeneration. J. Mater. Chem. B 2013, 1, 3607-3616. [CrossRef]

36. Vittorio, O.; Cojoc, M.; Curcio, M.; Spizzirri, U.G.; Hampel, S.; Nicoletta, F.P.; Iemma, F.; Dubrovska, A.; Kavallaris, M.; Cirillo, G. Polyphenol Conjugates by Immobilized Laccase: The Green Synthesis of Dextran-Catechin. Macromol. Chem. Phys. 2016, 217, 1488-1492. [CrossRef]

37. Hadi, S.; Artanti, A.N.; Rinanto, Y.; Wahyuni, D.S.C. Curcuminoid content of Curcuma longa L. and Curcuma xanthorrhiza rhizome based on drying method with NMR and HPLC-UVD. In IOP Conference Series: Materials Science and Engineering; IOP Publishing: Bristol, UK, 2018.

38. Garcia, D.R.; Lavignac, N. Poly(amidoamine)-BSA conjugates synthesised by Michael addition reaction retained enzymatic activity. Polym. Chem. 2016, 7, 7223-7229. [CrossRef]

39. Liu, C.; Liu, H.; Lu, C.; Tang, K.; Zhang, Y. Polyethyleneimine-modified graphene oxide/PNIPAm thermoresponsive hydrogels with rapid swelling/deswelling and improved mechanical properties. J. Mater. Sci. 2017, 52, 11715-11724. [CrossRef]

40. Vittorio, O.; Brandl, M.; Cirillo, G.; Kimpton, K.; Hinde, E.; Gaus, K.; Yee, E.; Kumar, N.; Duong, H.; Fleming, C.; et al. Dextran-Catechin: An anticancer chemically-modified natural compound targeting copper that attenuates neuroblastoma growth. Oncotarget 2016, 7, 47479-47493. [CrossRef]

41. Deb, A.; Vimala, R. Natural and synthetic polymer for graphene oxide mediated anticancer drug delivery-A comparative study. Int. J. Biol. Macromol. 2018, 107, 2320-2333. [CrossRef]

42. Jokar, S.; Pourjavadi, A.; Adeli, M. Albumin-graphene oxide conjugates; Carriers for anticancer drugs. RSC Adv. 2014, 4, 33001-33006. [CrossRef]

43. Zaloga, J.; Pöttler, M.; Leitinger, G.; Friedrich, R.P.; Almer, G.; Lyer, S.; Baum, E.; Tietze, R.; Heimke-Brinck, R.; Mangge, H.; et al. Pharmaceutical formulation of HSA hybrid coated iron oxide nanoparticles for magnetic drug targeting. Eur. J. Pharm. Biopharm. 2016, 101, 152-162. [CrossRef] [PubMed]

44. Spizzirri, U.G.; Cirillo, G.; Picci, N.; Iemma, F. Recent development in the synthesis of eco-friendly polymeric antioxidants. Curr. Org. Chem. 2014, 18, 2912-2927. [CrossRef]

45. Raveendran, R.; Bhuvaneshwar, G.S.; Sharma, C.P. Hemocompatible curcumin-dextran micelles as $\mathrm{pH}$ sensitive pro-drugs for enhanced therapeutic efficacy in cancer cells. Carbohydr. Polym. 2016, 137, 497-507. [CrossRef]

46. Iemma, F.; Puoci, F.; Curcio, M.; Parisi, O.I.; Cirillo, G.; Spizzirri, U.G.; Picci, N. Ferulic Acid as a Comonomer in the Synthesis of a Novel Polymeric Chain with Biological Properties. J. Appl. Polym. Sci. 2010, 115, 784-789. [CrossRef] 
47. Wang, Y.; Shi, Z.; Yin, J. Facile synthesis of soluble graphene via a green reduction of graphene oxide in tea solution and its biocomposites. ACS Appl. Mater. Interfaces 2011,3, 1127-1133. [CrossRef] [PubMed]

48. Song, H.; Hao, L.; Tian, Y.; Wan, X.; Zhang, L.; Lv, Y. Stable and water-dispersible graphene nanosheets: Sustainable preparation, functionalization, and high-performance adsorbents for $\mathrm{Pb}^{2+}$. ChemPlusChem 2012, 77, 379-386. [CrossRef]

49. Maddinedi, S.B.; Mandal, B.K.; Vankayala, R.; Kalluru, P.; Pamanji, S.R. Bioinspired reduced graphene oxide nanosheets using Terminalia chebula seeds extract. Spectrochim. Acta Part A 2015, 145, 117-124. [CrossRef] [PubMed]

50. Gurunathan, S.; Han, J.W.; Kim, E.S.; Park, J.H.; Kim, J.H. Reduction of graphene oxide by resveratrol: A novel and simple biological method for the synthesis of an effective anticancer nanotherapeutic molecule. Int. J. Nanomed. 2015, 10, 2951-2969. [CrossRef]

51. Goya, G.F.; Berquó, T.S.; Fonseca, F.C.; Morales, M.P. Static and dynamic magnetic properties of spherical magnetite nanoparticles. J. Appl. Phys. 2003, 94, 3520-3528. [CrossRef]

52. Bruvera, I.J.; Mendoza Zélis, P.; Pilar Calatayud, M.; Goya, G.F.; Sánchez, F.H. Determination of the blocking temperature of magnetic nanoparticles: The good, the bad, and the ugly. J. Appl. Phys. 2015, 118, 184304. [CrossRef]

53. Sanz, B.; Calatayud, M.P.; De Biasi, E.; Lima, E.; Mansilla, M.V.; Zysler, R.D.; Ibarra, M.R.; Goya, G.F. In silico before in vivo: How to predict the heating efficiency of magnetic nanoparticles within the intracellular space. Sci. Rep. 2016, 6, 38733. [CrossRef] [PubMed]

54. Jafari, Y.; Sabahi, H.; Rahaie, M. Stability and loading properties of curcumin encapsulated in Chlorella vulgaris. Food Chem. 2016, 211, 700-706. [CrossRef] [PubMed]

55. Gonçalves, G.; Vila, M.; Portolés, M.T.; Vallet-Regi, M.; Gracio, J.; Marques, P.A.A.P. Nano-graphene oxide: A potential multifunctional platform for cancer therapy. Adv. Healthc. Mater. 2014, 3, 956. [CrossRef]

56. Reis, A.V.; Guilherme, M.R.; Rubira, A.F.; Muniz, E.C. Mathematical model for the prediction of the overall profile of in vitro solute release from polymer networks. J. Colloid Interface Sci. 2007, 310, 128-135. [CrossRef] [PubMed]

57. Mao, H.Y.; Laurent, S.; Chen, W.; Akhavan, O.; Imani, M.; Ashkarran, A.A.; Mahmoudi, M. Graphene: Promises, facts, opportunities, and challenges in nanomedicine. Chem. Rev. 2013, 113, 3407-3424. [CrossRef] [PubMed]

58. Lorenzo, A.T.; Arnal, M.L.; Albuerne, J.; Müller, A.J. DSC isothermal polymer crystallization kinetics measurements and the use of the Avrami equation to fit the data: Guidelines to avoid common problems. Polym. Test. 2007, 26, 222-231. [CrossRef]

59. Mosaiab, T.; In, I.; Park, S.Y. Temperature and pH-tunable fluorescence nanoplatform with graphene oxide and BODIPY-conjugated polymer for cell imaging and therapy. Macromol. Rapid Commun. 2013, 34, 1408-1415. [CrossRef] [PubMed]

60. Ma, N.; Zhang, B.; Liu, J.; Zhang, P.; Li, Z.; Luan, Y. Green fabricated reduced graphene oxide: Evaluation of its application as nano-carrier for $\mathrm{pH}$-sensitive drug delivery. Int. J. Pharm. 2015, 496, 984-992. [CrossRef] [PubMed]

61. Kim, H.; Lee, D.; Kim, J.; Kim, T.I.; Kim, W.J. Photothermally triggered cytosolic drug delivery via endosome disruption using a functionalized reduced graphene oxide. ACS Nano 2013, 7, 6735-6746. [CrossRef]

62. Bai, J.; Liu, Y.; Jiang, X. Multifunctional PEG-GO/CuS nanocomposites for near-infrared chemo-photothermal therapy. Biomaterials 2014, 35, 5805-5813. [CrossRef] [PubMed]

63. Nahain, A.A.; Lee, J.E.; Jeong, J.H.; Park, S.Y. Photoresponsive fluorescent reduced graphene oxide by spiropyran conjugated hyaluronic acid for in vivo imaging and target delivery. Biomacromolecules 2013, 14, 4082-4090. [CrossRef] [PubMed]

64. Song, M.M.; Xu, H.L.; Liang, J.X.; Xiang, H.H.; Liu, R.; Shen, Y.X. Lactoferrin modified graphene oxide iron oxide nanocomposite for glioma-targeted drug delivery. Mater. Sci. Eng. C 2017, 77, 904-911. [CrossRef] [PubMed]

65. Liu, G.; Shen, H.; Mao, J.; Zhang, L.; Jiang, Z.; Sun, T.; Lan, Q.; Zhang, Z. Transferrin modified graphene oxide for glioma-targeted drug delivery: In vitro and in vivo evaluations. ACS Appl. Mater. Interfaces 2013, 5, 6909-6914. [CrossRef] [PubMed] 
66. Sharma, G.; Tyagi, A.K.; Singh, R.P.; Chan, D.C.F.; Agarwal, R. Synergistic anti-cancer effects of grape seed extract and conventional cytotoxic agent doxorubicin against human breast carcinoma cells. Breast Cancer Res. Treat. 2004, 85, 1-12. [CrossRef] [PubMed]

67. Lee, D.E.; Koo, H.; Sun, I.C.; Ryu, J.H.; Kim, K.; Kwon, I.C. Multifunctional nanoparticles for multimodal imaging and theragnosis. Chem. Soc. Rev. 2012, 41, 2656-2672. [CrossRef] [PubMed] 